\title{
Prevention of maternal cytomegalovirus infection: current status and future prospects
}

This article was published in the following Dove Press journal:

International Journal of Women's Health

17 February 2010

Number of times this article has been viewed

\author{
Jessica L Nyholm' \\ Mark R Schleiss ${ }^{2}$ \\ 'Department of Obstetrics, \\ Gynecology, and Women's Health, \\ and ${ }^{2}$ Department of Pediatrics, \\ University of Minnesota School \\ of Medicine, Minneapolis, MN, USA
}

Correspondence: Mark R Schleiss

Center for Infectious Disease and Microbiology Translational Research, University of Minnesota Medical School, 200I 6th Street SE, Minneapolis,

MN 55455, USA

Tel + I 6126269913

Fax + I 6126269924

Emailschleiss@umn.edu

\begin{abstract}
Human cytomegalovirus (CMV) infection is the most common cause of perinatal viral infection in the developed world, resulting in approximately 40,000 congenitally infected infants in the United States each year. Congenital CMV infection can produce varying degrees of neurodevelopmental disabilities. The significant impact of congenital CMV has led the Institute of Medicine to rank development of a CMV vaccine as a top priority. Vaccine development has been ongoing; however no licensed CMV vaccine is currently available. Treatment of pregnant women with CMV hyperimmune globulin has shown promising results, but has not been studied in randomized controlled trials. Education on methods to prevent CMV transmission, particularly among young women of child-bearing age, should continue until a CMV vaccine becomes available. The epidemiology, clinical manifestations, prevention strategies, and treatment of CMV infections are reviewed.
\end{abstract}

Keywords: cytomegalovirus, CMV vaccines, congenital CMV, CMV infection, immunoglobulin

\section{Introduction}

Human cytomegalovirus (CMV) is a ubiquitous beta-herpes virus that leads to congenital infection in $0.4 \%$ to $2.3 \%$ of all newborns. ${ }^{1}$ The risk of intrauterine transmission after primary CMV infection during pregnancy approaches $40 \%$, with an increased risk of adverse fetal effects if infection occurs during the first half of pregnancy. ${ }^{2}$ Of congenitally infected infants, approximately $10 \%$ are symptomatic at birth. Of the remaining $90 \%$ of infants who are asymptomatic at birth, $10 \%-15 \%$ will subsequently manifest evidence of permanent sequelae. ${ }^{3}$ Congenital CMV is a significant cause of neurodevelopmental disability, including sensorineural hearing loss (SNHL) and intellectual disability (previously referred to as "mental retardation"). More children suffer from long-term sequelae as a result of congenital CMV infection than Down syndrome or fetal alcohol syndrome. ${ }^{4}$ In this review, current concepts regarding the epidemiology, pathogenesis, and prevention of CMV infection are summarized, with an emphasis on strategies designed to improve awareness of the risk of CMV among women of childbearing age.

\section{Epidemiology}

CMV is found worldwide, with the rate of seropositivity affected by geographic, socioeconomic, and ethnic background. ${ }^{2,3}$ In developed countries, the prevalence of CMV seropositivity is $40 \%$ to $60 \%$ in individuals of middle to upper socioeconomic status and $\sim 80 \%$ among those of lower socioeconomic status. ${ }^{3}$ By comparison, virtually 
individuals in developing countries have been infected by CMV in early childhood. ${ }^{3}$ In the United States, the seroprevalence of CMV is higher among non-Hispanic blacks and Mexican Americans than among non-Hispanic whites. ${ }^{5}$

Congenital CMV infection can occur as the result of a primary CMV infection, reinfection with a new strain of CMV, or reactivation of a latent infection. ${ }^{6,7}$ Maternal immunity to CMV provides some protection against vertical transmission of the virus. If a primary CMV infection occurs in the period just prior to conception, the risk of transmission is $8.7 \%{ }^{8}$ Primary maternal CMV infection occurring in the first, second, and third trimester results in congenital infection in approximately $25 \%, 50 \%$, and $75 \%$ of fetuses, respectively. ${ }^{9}$ In contrast, the risk of $\mathrm{CMV}$ transmission to the fetus after a recurrent maternal infection is only 0.15 to $2 \%{ }^{10,11}$ Fowler et al demonstrated a $69 \%$ reduction in the risk of congenital CMV infection in future pregnancies in women who were seropositive for CMV when compared to seronegative women. ${ }^{12}$ However, despite the risk reduction preconception immunity affords, over $60 \%$ of infants with congenital CMV infection are born to mothers with immunity to CMV prior to pregnancy, reflecting the high rate of CMV seropositivity in the population. ${ }^{13}$ In populations with high maternal CMV seropositivity, the incidence of congenital $\mathrm{CMV}$ infection is greater than in populations of lower maternal seroprevalence. ${ }^{1}$

It has generally been believed that the fetuses of pregnant women with preconception immunity to CMV are somewhat protected against the most significant neurodevelopmental sequelae of congenital CMV infection. A study comparing women with preconception immunity to CMV to those who acquired primary CMV infection in pregnancy showed that the women with preconception immunity have a significant reduction in transmission of CMV to the fetus, as well as decreased severity of disease in infected infants. ${ }^{11}$ In that study, $25 \%$ of the infants whose mother had a primary infection had at least one sequela, compared with $8 \%$ when the infection was recurrent. However, subsequent studies have not demonstrated the same degree of protection conferred by preconception immunity in congenitally infected infants. Boppana et al studied infants with symptomatic congenital CMV infection as the result of both primary and recurrent maternal infection and found no difference in the severity of clinical findings between the two groups. ${ }^{14}$

\section{Pathogenesis}

CMV is a linear double-stranded DNA virus, and its genome is comprised of over 250 kilobase pairs. The three distinct regions of the CMV virus include the capsid containing the viral genome; the tegument layer containing phosphoproteins; and an outer lipid envelope containing glycoproteins. The capsid, which comprises 162 capsomere subunits arranged in icosahedral symmetry, houses the viral genome. ${ }^{15}$ The capsid is surrounded by the tegument of the CMV virion. A large number of proteins are located in the tegument. These tegument proteins, including phosphoprotein 65 (pp65), are some of the most immunogenic proteins in the virion, and are the immunodominant targets of T-lymphocytes responses to $\mathrm{CMV}^{16,17}$ Surrounding the tegument is the envelope, which contains an as yet incompletely defined number of virally encoded glycoproteins. The most abundant glycoproteins include gB complex, gM/gN complex, and $\mathrm{gH} / \mathrm{gL} / \mathrm{gO}$ complex. Seropositive individuals typically mount a neutralizing antibody response directed against these glycoproteins making these protein products potentially useful subunit vaccine candidates. ${ }^{18-20}$

CMV is a complex virus that appears to employ multiple strategies to evade the host immune system. ${ }^{21}$ A healthy, immunocompetent individual can control CMV infection, but only at great expense to the host immune system: remarkably, approximately $10 \%$ of both the $\mathrm{CD}^{+}$and $\mathrm{CD}^{+}$memory compartments in blood are specific for CMV-encoded proteins. ${ }^{22}$ The chronic, persistent nature of CMV, characterized by frequent episodes of asymptomatic reactivation and shedding, probably contributes to the ability of the virus to cause congenital infection even in women with long-standing preconception immunity.

\section{Congenital and postnatal transmission \\ Children as source of CMV}

Daycare centers are a significant source of CMV infection. Children less than three years of age with postnatally acquired CMV infection have been demonstrated to excrete CMV in their urine and saliva for 6 to 42 months. ${ }^{23}$ Children enrolled in daycare become infected with CMV between 15 and $70 \%$ of the time. ${ }^{24}$ Seronegative mothers with children in group daycare are at significant risk of acquiring CMV infection, with at least $50 \%$ of them seroconverting within 1 year of their child's CMV infection. ${ }^{25}$

\section{Breast-feeding}

CMV is excreted in the breast milk of seropositive women. ${ }^{26}$ The risk of CMV transmission in infants breast-fed by seropositive women shedding virus in their breast milk has been reported to be $58 \%$ to $69 \%{ }^{27,28} \mathrm{CMV}$ infection acquired 
in the postnatal period in healthy term infants typically is asymptomatic, only rarely producing any morbidity. There is no evidence that acquisition of CMV via breast milk leads to any adverse neurodevelopmental sequelae. In a study of CMV transmission through breast-feeding, all of the infants who acquired CMV infection had normal neurodevelopment at a mean follow-up of 51 months. ${ }^{28}$

While the safety of breast-feeding has been established in term infants in women shedding CMV virus, controversy exists on the safety of breast-feeding low birth weight, premature infants. Studies in low birth weight and very low birth weight preterm infants yield conflicting results with respect to the risk of developing symptomatic infection following breast milk acquisition of $\mathrm{CMV}^{29} \mathrm{~A}$ recent study of early postnatal CMV infection in preterm infants in an highly immune population demonstrated that symptomatic CMV infection was rare. ${ }^{30}$ Efforts to reduce the infectivity of breast milk from seropositive mothers has included freezing breast milk at $-20{ }^{\circ} \mathrm{C}$, Holder pasteurization, and short-term pasteurization. ${ }^{31}$ Of these methods, freeze-thaw is the best studied approach, and the technique most likely to retain the salutary immunological properties of breast milk. While freezing breast milk does lower the incidence of postnatally acquired CMV infection, it does not entirely eliminate the risk. ${ }^{32}$ It remains unclear whether interventions designed to interrupt breast milk transmission of CMV to low birth weight, premature babies improve either short-term or longterm outcomes for these infants.

\section{Other}

CMV can also be transmitted through close non-sexual contact, sexual activity, blood transfusions, and organ transplantation. ${ }^{4}$ Two methods are currently employed to decrease the risks of CMV transmission through blood transfusion, including utilizing leukocyte-reduced and CMV-negative blood products. Although leukocyte reduction has dramatically reduced the risk of transfusion-associated CMV infection, reports in the literature are conflicting about whether this intervention completely eliminates any risk of transmission. ${ }^{33,34}$ A recent survey of the American Association of Blood Bank (AABB) physician members showed that $65 \%$ of those responding felt both leukocyte-reduced and CMVnegative blood components were equivalent in their ability to prevent transfusion transmission of $\mathrm{CMV}^{35}$ However, despite the AABB survey results on attitudes toward leukocyte reduced blood products, fetuses and neonates are more likely to receive CMV-negative blood products compared to other groups receiving transfusions. ${ }^{35}$

\section{Clinical manifestations} Maternal CMV

Most CMV infections are subclinical in healthy immunocompetent hosts. ${ }^{1}$ When present, clinical symptoms of primary CMV infection include flu-like syndrome, fever, myalgias, pharyngitis, weakness, and fatigue. Laboratory abnormalities can include elevated liver transaminases and lymphocytosis. Most studies have shown that pregnancy does not appear to affect the clinical course of CMV infection. A more recent look at primary CMV infection in pregnancy by Nigro et al demonstrated substantially higher rate of symptoms associated with CMV infection than previously reported. ${ }^{36}$ In a cohort study, 32 women (31\%) diagnosed with primary CMV experienced either persistent fever or a flu-like illness. ${ }^{36}$ Practitioners should have a high index of suspicion when caring for at risk pregnant women with undiagnosed illness or fever.

\section{Congenital CMV}

Only $10 \%$ of congenitally infected fetuses are symptomatic at birth. Clinical symptoms include microcephaly, growth restriction, hepatosplenomegaly, chorioretinitis, jaundice, petechiae, hearing impairment, thrombocytopenia, hyperbilirubinemia, and anemia. ${ }^{13,37}$ The risk for neurologic sequelae is increased when infection occurs in the first trimester. ${ }^{38}$ The majority of infants with symptomatic congenital CMV infection at birth have evidence of central nervous system (CNS) impairment. In a study of 106 infants with symptomatic congenital CMV infection, $68 \%$ of infants had at least one clinical finding suggestive of neurologic impairment. ${ }^{37}$ It was reported in the early 1980 s that infants with symptomatic congenital CMV infection at birth have a $91 \%$ chance of developing long-term sequelae from the infection, and a $29 \%$ death rate, although advances in neonatal intensive care make mortality much less likely today. ${ }^{39}$ Of infants with asymptomatic congenital CMV infection at birth, 10\% to $15 \%$ will go on to develop symptoms, typically manifested as SNHL.

Congenital CMV infection is the most common nongenetic cause of SNHL in children. In the DECIBEL study, $23 \%$ of children with profound SNHL had congenital CMV infection. ${ }^{40}$ Permanent hearing loss occurs in approximately $14 \%$ of children with congenital CMV infection. ${ }^{41}$ SNHL from congenital CMV can present later in childhood. Approximately $6 \%$ to $23 \%$ of children with congenital CMV infection who are asymptomatic at birth will subsequently develop hearing loss. ${ }^{42}$ However, symptomatic infection at 
birth appears to be much more likely than asymptomatic infection to be associated with delayed SNHL, with a reported rate of delayed-onset hearing loss in symptomatic newborns of $33.7 \%{ }^{43}$

\section{Diagnosis}

\section{Diagnosis of maternal infection}

Diagnosis of maternal primary CMV infection can be challenging. Maternal primary CMV infection is confirmed if there is documented IgG seroconversion; however, most women do not have a baseline pre-pregnancy serology for comparison. A second method to diagnose primary CMV infection is to test for CMV-specific IgM, which is an indicator of recent or active CMV infection. Several problems exist with CMV IgM as a screening test. First, CMV IgM can be present for up to 9 months after a primary infection. ${ }^{2}$ Second, $\mathrm{CMV}$ IgM can be produced in both recurrent infections, as well as following reactivation of infection; thus, the finding of IgM antibodies does not allow discrimination of the timing of infection. ${ }^{44}$ Third, there is discordance among commercially available kits for CMV IgM, as well as false positive results. ${ }^{45}$ The AxSYM CMV IgM assay is very sensitive when compared to other commercial assays. ${ }^{46} \mathrm{~A}$ highly sensitive IgM assay can identify more pregnancies at risk.

In pregnant women with CMV-specific IgM, anti-CMV IgG avidity testing can be utilized to differentiate primary CMV infection from reactivation of latent infection or reinfection. ${ }^{44}$ Low avidity indices are indicative of an acute or recent primary CMV infection, and persist for approximately 18 to 20 weeks. ${ }^{44}$ Lazzarotto et al demonstrated that if the CMV IgG avidity index is performed prior to 18 weeks gestation, it has $100 \%$ sensitivity for detecting pregnancies at risk for transmitting CMV to the fetus, however the sensitivity is decreased to only $62.5 \%$ if the test is performed after 20 weeks gestation. ${ }^{47}$ Additionally, a recent CMV infection can be excluded if a high avidity is demonstrated in the first 12 to 16 weeks of pregnancy. If high avidity antibodies are present in the first trimester, a pregnancy is unlikely to result in symptomatic congenital transmission. In pregnancies where primary maternal infection is confirmed, further evaluation is directed toward determining if the fetus is infected (see Figure 1).

\section{Diagnosis of fetal infection}

Ultrasound can detect anomalies associated with CMV congenital infection, although many of the findings are non-specific. Prenatal ultrasonographic findings of congenital CMV infection include intrauterine growth restriction
(IUGR), microcephaly, ventriculomegaly, periventricular calcifications, echogenic bowel, hydramnios, hydrops, pleural effusion, and placental enlargement. ${ }^{48}$ The sensitivity of ultrasound to detect congenital CMV infection is poor given that the majority of congenitally infected infants are asymptomatic. In a study of 600 pregnant women with primary $\mathrm{CMV}$ infection, abnormal ultrasound findings were detected in 51/600 (8.5\%) of those pregnancies and in 23/154 (14.9\%) fetuses with documented congenital infection. ${ }^{48}$ The positive predictive value of an abnormal ultrasound predicting symptomatic congenital infection in women with primary CMV infection was only $35.3 \%$ when fetal infection status was unknown, compared to $78.3 \%$ when congenital CMV infection was confirmed. ${ }^{48}$

Fetal infection can be diagnosed by documenting the presence of CMV in the amniotic fluid (AF), most typically demonstrated by PCR analysis (below). Amniocentesis should be offered to women with documented seroconversion, serologic studies suggestive of a primary CMV infection, or abnormal ultrasound findings consistent with congenital CMV infection. The drawback of definitive testing is the risk associated with invasive diagnostic testing. The risk of procedure-related pregnancy loss has been demonstrated to be approximately $1 / 300$ to $1 / 500 .{ }^{49,50}$ The risk of iatrogenic vertical CMV transmission through amniocentesis is minimal. ${ }^{51}$

The timing of diagnostic testing is important. Amniocentesis for fetal diagnosis of congenital CMV infection should be performed after 21 to 23 weeks gestation, and at least 6 weeks after documentation of primary maternal infection, as earlier testing can lead to false negative results. ${ }^{52,53}$ In cases where maternal seroconversion occurs in the first trimester, the interval between seroconversion and testing of the AF may need to be increased. ${ }^{52}$ The timing of diagnostic testing is due to the fact that CMV is excreted through the fetal urine at detectable levels 6 to 9 weeks after maternal infection, and fetal urination is increased after 20 to 21 weeks gestation. When testing $\mathrm{AF} \geq 6$ weeks after maternal infection and $\geq 23$ weeks gestation the sensitivity of prenatal diagnosis of congenital CMV infection increased from $45 \%$ to $55 \%$ to $95.5 \% .^{52}$

AF can be evaluated with CMV viral culture and CMV polymerase chain reaction (PCR). The drawback of viral culture is that it can yield false negative results, and it requires a lengthy period of time to grow the virus in the laboratory (up to 6 weeks). PCR of the AF to detect CMV has a sensitivity and specificity of $90 \%$ to $98 \%$ and $92 \%$ to $98 \%$, respectively. ${ }^{54}$ Studies attempting to determine the 




Figure I Suggested guidelines for management and counseling of women with primary cytomegalovirus (CMV) infection during pregnancy. While no single maternal test is diagnostic, they can be useful in aiding further management and counseling of pregnant women with suspected primary CMV infection. Fetal ultrasound and definitive diagnostic testing for congenital infection should be offered when primary maternal CMV infection is suspected.

threshold of CMV viral load that is predictive of symptomatic congenital infection and/or sequelae have yielded conflicting results. Lazzarotto et al demonstrated that if the AF viral load is $\geq 10^{3}$ copies $/ \mathrm{mL}$ the risk for congenital infection is $100 \%$, and that the presence of viral load of $\geq 10^{5}$ copies $/ \mathrm{mL}$ is predictive of symptomatic congenital infection..$^{55}$ Additionally, Lazzarotto et al found that an AF PCR level of $<500$ copies $/ \mathrm{mL}$ is unlikely to be associated with symptomatic congenital infection. ${ }^{54}$ Other studies have not demonstrated clear viral load cut-offs correlating with fetal outcomes. ${ }^{56,57}$ While the viral load is generally greater in symptomatic infections when compared to asymptomatic infections, considerable overlap exists. ${ }^{54,56}$ The analysis of viral load by PCR is also fraught with uncertainty given that there are a great number of PCR assays, differing in primer sequence, method of PCR, and technique for quantification. If the AF CMV PCR and viral culture are negative, then congenital CMV infection is unlikely.

Counseling women with primary CMV infection accurately in pregnancy is important. Guerra et al demonstrated that accurate interpretation and counseling of women with positive CMV screening can decrease the rate of termination of pregnancy. ${ }^{58}$ Women with no evidence of CMV infection in the AF are likely to have an uninfected neonate. Women with CMV present in the AF should be counseled that there is a $10 \%$ risk of symptomatic congenital infection and a $90 \%$ chance of an asymptomatic congenital infection at birth. However, if the primary maternal CMV infection occurred in early pregnancy, the risk of an infected fetus demonstrating symptoms at birth is increased to between $20 \%$ and $30 \%$. $^{38,59}$ 
Fetuses with documented congenital CMV infection and ultrasound abnormalities have a poor prognosis, especially if cerebral abnormalities are detected. ${ }^{60}$

\section{Postnatal diagnosis of congenital infection}

In the evaluation of a newborn infant with possible congenital $\mathrm{CMV}$, care must be taken to not rely on antibody titers in the infant (so-called "TORCH" titers) because these are seldom of value in establishing the diagnosis of congenital CMV. The finding of CMV antibodies in an infant may simply reflect transplacental transfer of IgG, and IgM assays are fraught with the same issues regarding sensitivity and specificity in the newborn as they are in the mother. ${ }^{44,45}$ The most important diagnostic studies in the evaluation of suspected CMV disease are virologic studies, not serologic studies, including viral culture and PCR. CMV may be cultured from virtually any body fluid or organ system. Blood, urine, saliva, cerebrospinal fluid, bronchoalveolar lavage fluid, and tissues from biopsy specimens are all appropriate specimens for culture. The specimen is inoculated on to human cells (usually human foreskin fibroblasts) and the cell culture is monitored for the development of the characteristic CMV-associated cytopathic effect. CMV may grow slowly in culture, requiring up to 6 weeks of incubation. Culture identification is enhanced by centrifugation techniques, followed by monoclonal-antibody detection, referred to as the "shell-vial" assay. PCR amplification of CMV DNA from clinical specimens is a useful adjunct to culture techniques, and in recent years is increasingly being employed in place of viral culture for diagnosis of CMV infection. ${ }^{54}$ The information derived from PCR not only helps establish the diagnosis of CMV infection, but quantitative data may be of value in establishing prognosis, since there is evidence that infants with higher viral loads may portend an increased risk of development of SNHL; these infants, accordingly, may be more likely than infants with low viral load to benefit from antiviral therapy with ganciclovir. ${ }^{61}$

\section{CMV screening Maternal CMV screening}

Routine maternal screening for CMV infection is controversial. Currently neither the American College of Obstetricians and Gynecologists (ACOG) nor the Centers for Disease Control and Prevention (CDC) recommend routine serologic screening for CMV infection in pregnancy. ${ }^{62,63}$ Several problems exist with routine maternal serologic screening for CMV. First, if maternal immunity to CMV is documented, it does not rule out the possibility of congenital CMV infection through infection with a new CMV strain or reactivation of maternal CMV. Second, diagnosis of an in utero CMV infection does not necessarily predict symptomatic disease or sequelae in the infant upon completion of the pregnancy. Third, there is no established, evidence-based treatment available for fetal CMV infection in the pregnant patient. Finally, maternal screening may produce undue anxiety, particularly if screening is performed without adequate counseling to educate the patient about the implications of a positive or negative screening test.

Another consideration in developing a CMV screening program is the cost-effectiveness of such measures. Cahill et al evaluated the cost-effectiveness of 3 screening strategies and found that universal screening for primary maternal CMV infection would be cost effective if treatment of affected pregnancies with CMV specific hyperimmune globulin (HIG) would result in a minimum of a $47 \%$ reduction in symptomatic CMV disease. ${ }^{64}$ Further studies with randomized controlled trials are needed to evaluate treatment options, including CMV HIG, to determine a screening program's ability to reduce morbidity of congenital CMV disease.

Until evidence-based treatment is available, efforts should be made on emphasizing preventative measures to all women who are attempting pregnancy, or who are currently pregnant. Screening of pregnant women should be limited to instances where there is a clinical suspicion of an active CMV infection, either due to maternal symptoms, or ultrasonographic abnormalities suggesting fetal anomalies or maldevelopment.

\section{Neonatal CMV screening}

Newborn screening (NBS) for endocrine and metabolic disorders has been successfully performed through collection and analysis of dried blood spot (DBS) specimens. Universal newborn hearing screening (UNHS) is currently employed and has been demonstrated to have a positive effect on language outcomes among children with permanent bilateral hearing loss. ${ }^{65}$

Congenital CMV infection is a known cause of SNHL; however, UNHS will miss up to $75 \%$ of cases of CMV-associated SNHL, since, as noted, hearing loss may be late-onset. This observation provides support for the concept of universal screening for congenital CMV.

Utilization of NBS for diagnosis of congenital CMV infection is currently being debated. NBS for CMV can be justified based the much higher incidence of congenital CMV infection than many other disorders included in NBS program, and its association with SNHL. The potential benefit of NBS for congenital CMV derives from the opportunity to 
identify children who require close surveillance, including audiological evaluation and neurodevelopmental assessment. Early intervention programs for SNHL and developmental concerns can then be instituted, if required. Since the majority of cases of SNHL associated with congenital CMV occur post-natally, as already noted, a normal NHS does not provide complete reassurance in an infant with congenital infection, and serial audiological evaluation is required. Additionally, screening could identify children who may benefit from antiviral treatment to prevent hearing loss.

Prior to the implementation of universal CMV screening, a sensitive, reliable, and cost effective screening test for CMV needs to be optimized needs to be established. CMV testing can be performed utilizing urine, saliva, or DBS. Viral culture of the urine has long been the gold standard laboratory test for the diagnosis of CMV infection in newborns. Given the time-consuming and costliness of viral culture, PCR has been increasingly utilized to detect CMV virus. PCR of DBS has recently been reported by a number of investigators as a useful technique for detecting congenital CMV infection. One objection to the use of DBS as the sole test for detecting congenital CMV is that the viral load in blood may often be lower than in saliva or urine, or that DNAemia may be absent altogether in a congenitally infected baby. This may make detection of DNA in the DBS relatively insensitive compared to urine or saliva in making the diagnosis of congenital $\mathrm{CMV}^{66}$ There have been many studies evaluating varying methods for CMV DNA detection by PCR with a wide range of sensitivities reported. ${ }^{67-69}$ Continued work toward identification of the optimal screening test is necessary.

Another hurdle in the development of a NBS program for CMV is the creation and oversight of programs to carry out screening. Two of the options that have been posed for congenital CMV NBS are 1) hospital-based program utilizing urine, saliva, or DBS specimens and 2) state NBS program using DBS. ${ }^{70}$

Before universal NBS for congenital CMV can become standard practice, a reliable and sensitive screening test needs to be identified, mechanisms for implementation of this screening test must be validated, and a plan for how to longitudinally monitor children indentified with congenital CMV through screening needs to be identified.

\section{Prevention}

Prevention of CMV transmission in women of childbearing age is of utmost importance in order to reduce the rate of congenital infection. Both the CDC workgroup and
ACOG recommend education on hygienic practices to prevent CMV viral transmission. ${ }^{62,71}$ Hygienic strategies are important in preventing CMV transmission given that the saliva and urine of infected children are significant sources of CMV infection among women who are pregnant. ${ }^{25}$ Preventative strategies include washing hands whenever there is contact with a child's saliva or urine, not sharing food, utensils, or cups, and not kissing a child on the mouth or cheek. $^{4,72}$

Education of women about the implications of acquiring CMV infection, particularly during pregnancy, is vital. A survey of women in 2005 showed that only 14\% of women knew what CMV was, but reported that following preventative measures for preventing an infection that could harm an unborn baby would generally be acceptable. ${ }^{73}$ The effectiveness of educating pregnant women on methods to prevent CMV transmission has been demonstrated. ${ }^{7-76}$ In a study where seronegative mothers with a child in group day care were instructed on measures to prevent CMV transmission, pregnant mothers had a significantly lower rate of $\mathrm{CMV}$ infection when compared to non-pregnant mothers attempting conception. ${ }^{75}$ Additionally, VauloupFellous et al recently demonstrated a lower CMV seroconversion rate after counseling pregnant women on hygienic measures. ${ }^{76,77}$

Despite the demonstrated success of education of pregnant women on hygienic measures to prevent CMV transmission, obstetricans are not providing uniform, appropriate counseling. A recent survey of the ACOG Collaborative Ambulatory Research Network (CARN) members revealed that less than half counseled their patients on methods to prevent CMV transmission and the importance of prevention of transmission. ${ }^{63}$ Additionally, results of the survey of the ACOG CARN members and a survey of physicians in the Netherlands demonstrated gaps in their knowledge of CMV transmission. ${ }^{63,78}$ Continued education of providers on CMV infection and prevention is important in order for accurate counseling of pregnant women.

Effective strategies to increase awareness of CMV and the methods to prevent its transmission are needed. Additionally, a systematic means to measure the success of these programs is required. Recently, Bate and Cannon have proposed a plan to identify effective behavioral interventions for prevention of congenital CMV based on a social marketing model. ${ }^{79}$ This paper provides a framework to identify and evaluate behavioral interventions aimed at encouraging pregnant women to follow preventative measures. ${ }^{79}$ Identification of effective means to educate pregnant women on CMV would 
allow for more focused use of resources, and could result in a reduction in CMV transmission.

\section{Therapy}

\section{Antiviral}

Antiviral agents currently licensed for the treatment of CMV infections include ganciclovir and its prodrugs valganciclovir, foscarnet, and cidofovir. Although there has been significant experience with the use of ganciclovir in the infected newborn (reviewed below), none of these agents have been formally approved by the US Food and Drug Administration (FDA) specifically for the treatment or prevention of CMV infections during pregnancy or for congenital CMV. ${ }^{80}$ There has been concern reported regarding the safety of treatment with antiviral medications in pregnancy. A case report of use of oral ganciclovir in a liver transplant patient in pregnancy did not show any evidence of teratogenicity. ${ }^{81}$ Ganciclovir has been demonstrated to cross the placenta, and therefore could in theory, be utilized to treat in utero congenital CMV infection. ${ }^{82}$ An observational study of 20 women with 21 fetuses with confirmed in utero CMV infection treated with oral valacyclovir demonstrated placental transfer of the drug, with therapeutic concentrations in the AF and a reductions of viral load in the fetal blood. ${ }^{83}$ There have been several case reports of treatment of congenital CMV infection in utero with oral, parenteral, or intra-amniotic ganciclovir with varying degrees of success. ${ }^{84-88}$ Although it is probably safe, prenatal treatment of fetal CMV infection with ganciclovir is currently not supported by the available data; further study with a randomized controlled trial is needed.

Despite a lack of formal FDA approval, there is good evidence supporting the treatment of congenital CMV infection with ganciclovir, based upon its demonstrated impact on SNHL outcomes. A randomized, controlled trial of 100 neonates with symptomatic congenital CMV infection treated with intravenous ganciclovir at a dose of $6 \mathrm{mg} / \mathrm{kg}$ every 12 hours for 6 weeks showed prevention of deterioration of hearing at 6 months. ${ }^{89}$ In a retrospective review of 9 children with symptomatic congenital CMV, none had progression of hearing loss following prolonged ganciclovir therapy. ${ }^{90}$ In another study, children with asymptomatic congenital CMV infection were treated with ganciclovir versus observation and followed over time. ${ }^{91}$ No children in the ganciclovir group had SNHL, while $11.1 \%$ in the observation group demonstrated evidence of SNHL over time. Valganciclovir has been more recently studied for the postnatal treatment of symptomatic congenital CMV, and is an attractive alternative to ganciclovir, because it can be administered orally. ${ }^{92}$
A trial is currently in progress comparing treatment with valganciclovir for 6 weeks versus 6 months, with the goal of examining whether prolonged therapy further improves neurodevelopmental outcomes, including SNHL. ${ }^{92}$

\section{Passive immunization}

Immunoglobulin therapy has been used to treat several conditions in pregnancy and is generally well tolerated. The mechanisms by which immuoglobulins act to treat many pregnancy-related conditions remain largely unknown. Treatment of a variety of viral infections with immunoglobulin has been valuable in disease control. Theoretical mechanisms include direct neutralization of virus particles; facilitation of antibody-directed natural killer cell activity; antibodydependent cellular cytotoxicity; and blocking of viral entry at the cell surface. ${ }^{93}$

Passive immunization with hyper-immune globulin (CMV HIG) has been studied for the in utero treatment and prevention of congenital CMV infection. CMV HIG is a pooled, high-titer immunoglobulin preparation derived from donors with high levels of CMV antibody. Improved perinatal outcomes after treatment of congenital CMV infection was first demonstrated in animal models. ${ }^{94,95}$ Nigro and colleagues completed a prospective study of CMV HIG for the treatment of pregnant women with primary CMV infection, including some women with confirmed fetal CMV infection. ${ }^{96}$ The women were enrolled in the "therapy" group if they had an amniocentesis and confirmed congenital CMV infection, as evidenced by a positive PCR in the AF, or the "prevention" group if they did not have an amniocentesis. In the therapy group only $1 / 31$ of the treated mothers delivered an infant with congenital CMV disease, compared to 7/14 mothers who were not treated with HIG. In the prevention group 6/37 mothers receiving HIG delivered infants with congenital CMV, compared to $19 / 47$ mothers who did not receive treatment. Overall, there was a statistically significant reduction of risk for congenital CMV infection in the HIG therapy group, and a reduction in CMV infection in the $\mathrm{HIG}$ prevention group. In a subsequent study by Nigro and colleagues, 3 fetuses treated with HIG had resolution of their ultrasonographically detected cerebral abnormalities; in contrast 2 untreated fetuses had persistence of their cerebral abnormalities. ${ }^{97}$

In addition to fetal effects, CMV HIG has been demonstrated to affect the placenta. In pregnancies treated with HIG there has been demonstration of significant reductions in placental thickness. ${ }^{97,98}$ The reduction in placental thickness observed following HIG treatment suggests that improved fetal outcomes are mediated, at least in part, 
through improved placental health and function, and not (only) through the salutary effect of immune globulin present in the fetal circulation. ${ }^{99}$

The mechanisms by which HIG works for the treatment and prevention of congenital CMV may be due to the virus neutralizing effect. Nigro et al demonstrated that women in the treatment group had significantly higher levels of CMV specific IgG concentration and IgG avidity after HIG treatment when compared to the untreated group. ${ }^{96}$ Symptomatic CMV disease may be secondary to inflammation in response to CMV infection. ${ }^{100,101}$ The immunomodulatory effects of HIG may decrease the inflammation, and subsequent tissue damage from CMV. Randomized controlled trials of HIG for treatment and prevention of congenital CMV infection are needed. Until such data are available, clinicians could give consideration to treatment with CMV HIG in pregnant patients with confirmed fetal CMV infection.

\section{Vaccines}

\section{Live attenuated virus vaccines}

It has been over three decades since the first live CMV vaccine candidate was tested in humans. ${ }^{102}$ A subsequent live attenuated CMV vaccine candidate, the Towne strain, was found to have a good safety profile and was immunogenic. ${ }^{103}$ A clinical trial of the Towne strain CMV vaccine in kidney transplant patients showed that the vaccine did not prevent CMV infection, but it did reduce the severity of CMV disease when compared to placebo controls. ${ }^{104}$ However, the Towne vaccine failed to prevent CMV infection in seronegative women who had children attending group day care when it was tested in a placebo-controlled trial. ${ }^{105}$ The lack of efficacy in this study was attributed to the decreased neutralizing titers produced after Towne vaccination when compared to infection by wild type virus. In addition, the laboratory-adapted Towne strain of CMV has genomic deletions which may affect the immunogenicity of the vaccine. With the goal of improving the immunogenicity of live, attenuated CMV vaccines, 4 "chimeric" vaccines were created which represented hybrids of the Towne strain and the less attenuated Toledo strain of $\mathrm{CMV}$, and tested in a phase one study; these vaccines were all well tolerated, although immunogenicity was difficult to assess. ${ }^{106}$ Additional study of the chimeric vaccines need to be performed in seronegative controls.

\section{Subunit vaccines}

\section{Purified recombinant glycoprotein B}

Additional vaccine approaches are currently being developed with the goal of inducing a potent virus-neutralizing antibody response. ${ }^{107}$ The CMV envelope glycoprotein B (gB) has been the most studied subunit vaccine candidate for this purpose, since it is a target of neutralizing antibody in all CMV-seropositive individuals. Animal models of gB vaccine have shown its ability to prevent congenital CMV infection and disease. ${ }^{108,109}$ Results of a phase II, placebo-controlled, randomized, double-blind trial of the recombinant $\mathrm{CMV}$ envelope gB with MF59 adjuvant were recently published. ${ }^{110}$ In this study, three doses of the CMV vaccine or placebo were administered at 0,1 , and 6 months to healthy women within 12 months postpartum. Women in the vaccine group were less likely to become infected with $\mathrm{CMV}$ than the placebo group ( $P=0.02$ ) with $18 / 225$ women becoming infected with CMV in the vaccine group, compared to $31 / 216$ in the placebo group.

\section{DNA vaccines}

DNA vaccines have been studied in both animal models and humans. In the guinea pig model gB DNA vaccination administered prior to conception offered some protection against congenital CMV transmission in the liveborn pups. ${ }^{111}$ A phase I study of a bivalent CMV DNA vaccine demonstrated safety and immunogenicity of the DNA vaccine. ${ }^{112}$ The effect of immune priming with a CMV DNA vaccine encoding pp65, IE1, and $\mathrm{gB}$ was tested by administering the Towne strain after vaccination and evaluating the immune response. ${ }^{113}$ There was a significant decrease in time to pp65 T-cell and $\mathrm{gB}$ antibody response in DNA primed subjects when compared to control subjects who were administered Towne strain only. DNA vaccines are currently being evaluated in the hematopoietic stem cell transplantation population toward the goal of reducing CMV disease in these individuals. $^{114}$

\section{Vector systems}

Vector systems utilize non-replicating vectors to express gene products of interest. Two examples of vector systems utilized in CMV vaccine development are the modified vaccinia virus Ankara (MVA) and an alphavirus vector based on an attenuated variant of Venezuelan equine encephalitis virus. MVA utilizes a highly attenuated poxvirus vector. The MVA vector system can express $\mathrm{gB}$, as well as the cell-mediated immunity targets pp65, and IE1. ${ }^{115}$ The alphavirus vector system produces virus-like replicon particles (VRP) that can express gB, pp65 and IE1. ${ }^{116}$ The alphavirus vector system has been studied in the in the guinea pig model and was found to induce both humoral and cellular immunity and improve pregnancy outomes. ${ }^{117}$ 


\section{Future prospects}

Recent advances in the understanding of CMV-cell interactions have lead to new insights into potential glycoprotein targets for vaccination. Recently, a new glycoprotein complex, including the gene products of the UL128-131 region of the viral genome, has been characterized. These proteins are necessary for CMV entry into epithelial cells. ${ }^{118,119}$ The live, attenuated Towne vaccine and the gB-based protein subunit vaccine are less effective than natural infection in inducing antibodies capable of neutralizing CMV infection in epithelial cells. Future optimization of CMV vaccines may require improvement in the humoral response to virally encoded proteins important in epithelial cell entry, particularly in view of the fact that most $\mathrm{CMV}$ infections are acquired at mucosal surfaces. ${ }^{120}$

\section{Conclusion}

CMV remains a significant public health concern. The neurologic disability from congenital CMV infection can be devastating. Antiviral drugs administered postnatally appear to decrease the severity of SNHL. CMV HIG has shown promising results for in utero treatment of fetal CMV infection, and possible prevention of congenital transmission, although randomized, blinded, controlled trials are lacking. CMV vaccine development continues to be a major public health priority. Until an effective CMV vaccine is licensed, education of young women regarding hygienic and behavioral approaches that can help prevent CMV transmission is essential. Obstetricians can lead the way in ensuring that appropriate counseling about the risks of CMV becomes a mainstay of prenatal care.

\section{Disclosures}

The authors report no conflicts of interest in this work. Supported by NIH R01HD044864 and HD038416.

\section{References}

1. Stagno S, Pass RF, Dworsky ME, Alford CA. Maternal cytomegalovirus infection and perinatal transmission. Clin Obstet Gynecol. 1982;25(3):563-576.

2. Stagno S, Pass RF, Cloud G, et al. Primary cytomegalovirus infection in pregnancy. Incidence, transmission to the fetus, and clinical outcome. JAMA. 1986;256(14):1904-1908.

3. Demmler GJ. Infectious Diseases Society of America and Centers for Disease Control: summary of a workshop on surveillance for congenital cytomegalovirus disease. Rev Infect Dis. 1991;13(2):315-329.

4. Cannon MJ, Finn Davis K. Washing our hands of the congenital cytomegalovirus disease epidemic. BMC Public Health. 2005;5:70-77.

5. Staras SAS, Dollard SC, Radford KW, Flanders WD, Pass RF, Cannon MJ. Seroprevalence of cytomegalovirus infection in the United States, 1988-1994. Clin Infect Dis. 2006;43(9):1143-1151.

6. Stagno S, Reynolds DW, Huang ES, Thames SD, Smith RJ, Alford CA. Congenital cytomegalovirus infection. $N$ Engl J Med. 1977;296(22):1254-1258.
7. Boppana SB, Rivera LB, Fowler KB, Mach M, Britt WJ. Intrauterine transmission of cytomegalovirus to infants of women with preconceptional immunity. N Engl J Med. 2001;344(18):1366-1371.

8. Revello MG, Zavattoni M, Furione M, Fabbri E, Gerna G. Preconceptional primary human cytomegalovirus infection and risk of congenital infection. J Infect Dis. 2006;193(6):783-787.

9. Bodeus M, Hubinont C, Goubau P. Increased risk of cytomegalovirus transmission in utero during late gestation. Obstet Gynecol. 1999;93(5 Pt 1):658-660.

10. Stagno S, Whitley RJ. Herpesvirus infections of pregnancy. Part I: Cytomegalovirus and Epstein-Barr virus infections. $N$ Engl J Med. 1985;313(19):1270-1274

11. Fowler KB, Stagno S, Pass RF, Britt WJ, Boll TJ, Alford CA. The outcome of congenital cytomegalovirus infection in relation to maternal antibody status. N Engl J Med. 1992;326(10):663-667.

12. Fowler KB, Stagno S, Pass RP. Maternal immunity and prevention of congenital cytomegalovirus infection. JAMA. 2003;289(8):1008-1011.

13. Ornoy A, Diav-Citrin O. Fetal effects of primary and secondary cytomegalovirus infection in pregnancy. Reprod Toxicol. 2006;21(4):399-409.

14. Boppana SB, Fowler KB, Britt WJ, Stagno S, Pass RF. Symptomatic congenital cytomegalovirus infection in infants born to mothers with preexisting immunity to cytomegalovirus. Pediatrics. 1999;104(1):55-60.

15. Chen DH, Jiang H, Lee M, Liu F, Zhou ZH. Three-dimensional visualization of tegument/capsid interactions in the intact human cytomegalovirus. Virology. 1999;260(1):10-16.

16. Landini MP, La Placa M. Humoral immune response to human cytomegalovirus proteins: a brief review. Comp Immun Microbiol Infect Dis. 1991;14(2):97-105.

17. Kern F, Bunde T, Faulhaber N, et al. Cytomegalovirus (CMV) phosphoprotein 65 makes a large contribution to shaping the $\mathrm{T}$ cell repertoire in CMV-exposed individuals. J Infect Dis. 2002;185(12):1709-1716.

18. Navarro D, Lennette E, Tugizov S, Pereira L. Humoral immune response to functional regions of human cytomegalovirus glycoprotein B. J Med Virol. 1997;52(4):451-459.

19. Rasmussen L, Matkin C, Spaete R, Pachl C, Merigan TC. Antibody response to human cytomegalovirus glycoproteins $\mathrm{gB}$ and $\mathrm{gH}$ after natural infection in humans. J Infect Dis. 1991;164(5):835-842.

20. Mach M, Kropff B, Dal Monte P, Britt W. Complex formation by human cytomegalovirus glycoproteins M (gpUL100) and N (gpUL73). JVirol. 2000;74(24):11881-11892.

21. Powers C, DeFilippis V, Malouli D, Früh K. Cytomegalovirus immune evasion. Curr Top Microbiol Immunol. 2008;325:333-359.

22. Sylwester AW, Mitchell BL, Edgar JB, et al. Broadly targeted human cytomegalovirus-specific $\mathrm{CD}^{+}{ }^{+}$and $\mathrm{CD}^{+} \mathrm{T}$ cells dominate the memory compartments of exposed subjects. J Exp Med. 2005;202(5):673-685.

23. Adler SP. Molecular epidemiology of cytomegalovirus: a study of factors affecting transmission among children at three day-care centers. Pediatr Infect Dis J. 1991;10(8):584-590.

24. Adler SP. Cytomegalovirus transmission and child day care. Adv Pediatr Infect Dis. 1992;7:109-122.

25. Adler SP. Cytomegalovirus and child day care: risk factors for maternal infection. Pediatr Infect Dis J. 1991;10(8):590-594.

26. Stagno S. Breastfeeding and the transmission of cytomegalovirus infections. Ital J Pediatr. 2002;28:275-280.

27. Dworsky M, Yow M, Stagno S, Pass RF, Alford C. Cytomegalovirus infection of breast milk and transmission in infancy. Pediatrics. 1983;72(3):295-299.

28. Stagno S, Reynolds DW, Pass RF, Alford CA. Breast milk and the risk of cytomegalovirus infection. N Engl J Med. 1980;302(19):1073-1076.

29. Schleiss MR. Acquisition of human cytomegalovirus infection in infants via breast milk: natural immunization or cause for concern? Rev Med Virol. 2006;16(2):73-82.

30. Mussi-Pinhata MM, Yamamota AY, do Carmo Rego MA, Pinto PC, da Motta MS, Calixto C. Perinatal or early-postnatal cytomegalovirus infection in preterm infants under 34 weeks gestation born to CMV-seropositive mothers within a high-seroprevalence population. $J$ Pediatr. 2004;145(5):685-688. 
31. Hamprecht K, Maschmann J, Müller D, et al. Cytomegalovirus (CMV) inactivation in breast milk: reassessment of pasteurization and freezeThawing. Pediatr Res. 2004;56(4):529-535.

32. Buxmann H, Miljak A, Fischer D, Rabenau HF, Doerr HW, Schloesser RL. Incidence and clinical outcome of cytomegalovirus transmission via breast milk in preterm infants $\leq 31$ weeks. Acta Paediatr. 2009;98(2):270-276.

33. Allain JP, Stramer SL, Carneira-Proietti AB, et al. Transfusiontransmitted infectious diseases. Biologicals. 2009;37(2):71-77.

34. Vamvakas EC. Is white blood cell reduction equivalent to antibody screening in preventing transmission of cytomegalovirus by transfusion? A review of the literature and meta-analysis. Transfus Med Rev. 2005;19(3):181-199.

35. Smith D, Lu Q, Yuan S, Goldfinger D, Fernando LP, Ziman A. Survey of current practice for prevention of transfusion-transmitted cytomegalovirus in the United States: leucoreduction vs cytomegalovirusseronegative. Vox Sang. 2010;98(1):29-36

36. Nigro G, Anceschi MM, Cosmi EV; for Congenital Cytomegalic Disease Collaborating Group. Clinical manifestations and abnormal laboratory findings in pregnant women with primary cytomegalovirus infection. Br J Obstet Gynaecol. 2003;110:572-577.

37. Boppana SB, Pass RF, Britt WJ, Stagno S, Alford CA. Symptomatic congenital cytomegalovirus infection: neonatal morbidity and mortality. Pediatr Infect Dis J. 1992;11(2):93-99.

38. Pass RF, Fowler KB, Boppana SB, Britt WJ, Stagno S. Congenital cytomegalovirus infection following first trimester maternal infection: symptoms at birth and outcome. J Clin Virol. 2006;35(2):216-220.

39. Stagno S, Pass RF, Alford CA. Perinatal infections and maldevelopment. In: Bloom AD, James LS, editors. The Fetus and the Newborn. New York: Alan R. Liss, Inc; 1981:31-50.

40. Korver AH, de Vries JJC, Konings S, et al; DECIBEL collaborative study group. Congenital cytomegalovirus infection in young children with permanent bilateral hearing impairment in the Netherlands. J Clin Virol. 2009;46 Suppl 4:S27-S31.

41. Grosse S, Ross DS, Dollard SC. Congenital cytomegalovirus (CMV) infection as a cause of permanent bilateral hearing loss: a quantitative assessment. J Clin Virol. 2008;41(2):57-62.

42. Fowler KB, Boppana SB. Congenital cytomegalovirus (CMV) infection and hearing deficit. J Clin Virol. 2006;35(2):226-231.

43. Rosenthal LS, Fowler KB, Boppana SB, et al. Cytomegalovirus shedding and delayed sensorineural hearing loss. Pediat Infect Dis $J$. 2009;28(6):515-520.

44. Lazzarotto T, Spezzacatena P, Pradelli P, Abate DA, Varani S, Landini MP. Avidity of immunoglobulin $\mathrm{G}$ directed against human cytomegalovirus during primary and secondary infections in immunocompetant and immunocompromised subjects. Clin Diagn Lab Immunol. 1997;4(4): 469-473.

45. Lazzarotto T, Brojanac S, Maine GT, Landini MP. Search for cytomegalovirus-specific immunoglobulin $\mathrm{M}$ : comparison between a new western blot, conventional western blot, and nine commercially available assays. Clin Diagn Lab Immunol. 1997;4(4):483-486.

46. Gentile M, Galli C, Pagnotti P, et al. Measurement of the sensitivity of different commercial assays in the diagnosis of CMV infection in pregnancy. Eur J Clin Microbiol Infect Dis. 2009;28(8):977-981.

47. Lazzarotto T, Varani S, Spezzacatena P, et al. Maternal IgG avidity and IgM detected by blot as diagnostic tools to identify pregnant women at risk for transmitting cytomegalovirus. Viral Immunol. 2000;13(1):137-141.

48. Guerra B, Simonazzi G, Puccetti C, et al. Ultrasound prediction of symptomatic congenital cytomegalovirus infection. Am J Obstet Gynecol. 2008;198:380.e1-380.e7.

49. Mazza V, Pati M, Bertucci E, et al. Age-specific risk of fetal loss post second trimester amniocentesis: analysis of 5043 cases. Prenat Diagn. 2007;(2)27:180-183.

50. Eddleman KA, Malone FD, Sullivan L, et al; for First and Second Trimester Evaluation of Risk (FASTER) Trial Research Consortium. Pregnancy loss rates after midtrimester amniocentesis. Obstet Gynecol. 2006;108(5):1067-1072.
51. Revello MG, Furione M, Zavattoni M, et al. Human cytomegalovirus (HCMV) DNAemia in the mother at amniocentesis as a risk factor for iatrogenic HCMV infection of the fetus. J Infect Dis. 2008;197(4): 593-596.

52. Bodéus M, Hubinont C, Bernard P, Bouckaert A, Thomas K, Goubau P. Prenatal diagnosis of human cytomegalovirus by culture and polymerase chain reaction: 98 pregnancies leading to congenital infection. Prenat Diagn. 1999;19(4):314-317.

53. Donner C, Liesnard C, Brancart F, Rodesch F. Accuracy of amniotic fluid testing before 21 weeks' gestation in prenatal diagnosis of congenital cytomegalovirus infection. Prenat Diagn. 1994;13(4):1055-1059.

54. Lazzarotto T, Guerra B, Lanari M, Gabrielli L, Landini MP. New advances in the diagnosis of congenital cytomegalovirus infection. J Clin Virol. 2008;41(3):192-197.

55. Lazzarotto T, Varani S, Guerra B, Nicolosi A, Lanari M, Landini MP. Prenatal indicators of congenital cytomegalovirus infection. $J$ Pediat. 2000;137(1):90-95

56. Revello MG, Gerna G. Pathogenesis and prenatal diagnosis of human cytomegalovirus infection. J Clin Virol. 2004;29(2):71-83.

57. Revello MG, Zavattoni M, Furione M, Baldanti F, Gerna G. Quantification of human cytomegalovirus DNA in amniotic fluid of mothers of congenitally infected fetuses. J Clin Microbiol. 1999;37(10): $3350-3352$

58. Guerra B, Simonazzi G, Banfi A, et al. Impact of diagnostic and confirmatory tests and prenatal counseling on the rate of pregnancy termination among women with positive cytomegalovirus immunoglobulin $\mathrm{M}$ antibody titers. Am J Obstet Gynecol. 2007;196:221.e1-221.e6.

59. Enders G, Bäder U, Lindemann L, Schalasta G, Daiminger A. Prenatal diagnosis of congenital cytomegalovirus infection in 189 pregnancies with known outcome. Prenat Diagn. 2001;21(5):362-377.

60. Benoist G, Salomon LJ, Jacquemard F, Daffos F, Ville Y. The prognostic value of ultrasound abnormalities and biological parameters in blood of fetuses infected with cytomegalovirus. Br J Obstet Gynaecol. 2008;115:823-829.

61. Boppana SB, Fowler KB, Pass RF, et al. Congenital cytomegalovirus infection: association between virus burden in infancy and hearing loss. J Pediatr. 2005;146(6):817-823.

62. American College of Obstetricians and Gynecologists. ACOG practice bulletin. Perinatal viral and parasitic infections. Number 20, September 2000. (Replaces educational bulletin number 177, February 1993). American College of Obstetricians and Gynecologists. Int J Gynaecol Obstet. 2002;76(1):95-107.

63. Ross DS, Rasmussen SA, Cannon MJ, et al. Obstetrician/gynecologists' knowledge, attitudes, and practices regarding prevention of infections in pregnancy. J Womens Health. 2009;18(8):1187-1193.

64. Cahill AG, Odibo AO, Stamilio DM, Macones GA. Screening and treating for primary cytomegalovirus infection in pregnancy: where do we stand? A decision-analytic and economic analysis. Am J Obstet Gynecol. 2009;201:466e1-466e7.

65. Kennedy CR, McCann DC, Campbell MJ, et al. Language ability after early detection of permanent childhood hearing impairment. $N$ Engl $J$ Med. 2006;354(20):2131-2141.

66. Inoue N, Koyano S. Evaluation of screening tests for congenital cytomegalovirus infection. Pediatr Infect Dis J. 2008;27(2):182-184.

67. Choi KY, Schimmenti LA, Jurek AM, et al. Detection of cytomegalovirus DNA in dried blood spots of Minnesota infants who do not pass newborn hearing screening. Pediat Infect Dis J. Epub 2009;28(12).

68. Atkinson C, Walter S, Sharland M, et al. Use of stored dried blood spots for retrospective diagnosis of congenital CMV. J Med Virol. 2009;81(8):1394-1398.

69. Vauloup-Fellous C, Ducroux A, Couloigner V, et al. Evaluation of cytomegalovirus (CMV) DNA quantification in dried blood spots: retrospective study of CMV congenital infection. J Clin Microbiol. 2007;45(11):3804-3806.

70. Grosse SD, Dollard S, Ross DS, Cannon M. Newborn screening for congenital cytomegalovirus: options for hospital-based and public health programs. J Clin Virol. 2009. [Epub ahead of print]. 
71. Ross DS, Dollard SC, Victor M, Sumartojo E, Cannon MJ. The epidemiology and prevention of congenital cytomegalovirus infection and disease: activities of the Centers for Disease Control and Prevention Workgroup. J Womens Health. 2006;15(3):224-229.

72. Anderson B, Schulkin J, Ross DS, Rasmussen SA, Jones JL, Cannon MJ. Knowledge and practices of obstetricians and gynecologists regarding cytomegalovirus infection during pregnancy - United States, 2007. MMWR. 2008;57(3):65-68.

73. Ross DS, Victor M, Sumartojo E, Cannon MJ. Women's knowledge of congenital cytomegalovirus: results from the 2005 HealthyStyles ${ }^{\mathrm{TM}}$ survey. J Womens Health. 2008;17(5):849-858.

74. Adler SP, Finney JW, Manganello AM, Best AM. Prevention of childto-mother transmission of cytomegalovirus by changing behaviors: a randomized controlled trial. Pediatr Infect Dis J. 1996;15(3):240-246.

75. Adler SP, Finney JW, Manganello AM, Best AM. Prevention of child-to-mother transmission of cytomegalovirus among pregnant women. J Pediatr. 2004;145(4):485-491.

76. Vauloup-Fellous C, Picone O, Cordier A, et al. Does hygiene counseling have an impact on the rate of CMV primary infection during pregnancy? Results of a 3-year prospective study in a French hospital. J Clin Virol. 2009. [Epub ahead of print].

77. Picone O, Vauloup-Fellous C, Cordier A, et al. A 2-year study on cytomegalovirus infection during pregnancy in a French hospital. BJOG. 2009;116(6):818-823.

78. Kover AMH, de Vries JJC, de Jong JW, Dekker FW, Vossen ACTM, Oudesluys-Murphy AM. Awareness of congenital cytomegalovirus among doctors in the Netherlands. J Clin Virol. 2009. [Epub ahead of print].

79. Bate SL, Cannon MJ. A social marketing approach to building a behavioral intervention for congenital cytomegalovirus. Health Promotion Practice. 2009. [Epub ahead of print].

80. Biron KK. Antiviral drugs for cytomegalovirus diseases. Antiviral Res. 2006;71:154-163

81. Pescovitz MD. Absence of teratogenicity of oral ganciclovir used during early pregnancy in a liver transplant recipient. Transplantation. 1999;67(5):758-759.

82. Brady RC, Schleiss MR, Witte DP, Siddiqi TA, Frame PT. Placental transfer of ganciclovir in woman with acquired immunodeficiency syndrome and cytomegalovirus disease. Pediat Infect Dis. 2002;21(8): 796-797.

83. Jacquemard F, Yamamoto M, Costa J, et al. Maternal administration of valacyclovir in symptomatic intrauterine cytomegalovirus infection. Br J Obstet Gynecol. 2007;114:1113-1121.

84. Puliyanda DP, Silverman NS, Lehman D, et al. Successful use of oral ganciclovir for the treatment of intrauterine cytomegalovirus infection in a renal allograft recipient. Transpl Infect Dis. 2005;7:71-74.

85. Miguelez M, Gonzalez A, Perez R. Severe cytomegalovirus hepatitis in a pregnant woman treated with ganciclovir. Scand J Infect Dis. 1998;30(3):304-305.

86. Revello MG, Percivalle E, Baldanti F, et al. Prenatal treatment of congenital human cytomegalovirus infection by fetal intravascular administration of ganciclovir. Clin Diagn Virol. 1993;1(1):61-67.

87. Revello MG, Gerna G. Diagnosis and implications of cytomegalovirus infection in pregnancy. Fet Matern Med Rev. 1999;11(3):117-134.

88. Brady RC, Schleiss MR, Witte D, Siddiqi TA, Frame PT. Placental transfer of ganciclovir in a woman with acquired immunodeficiency syndrome and cytomegalovirus disease. Pediatr Infect Dis J. 2002;21(8):796-797.

89. Kimberlin DW, Lin CY, Sánchez PJ, et al. Effect of ganciclovir therapy on hearing in symptomatic congenital cytomegalovirus disease involving the central nervous system: a randomized, controlled trial. J Pediatr. 2003;143(1):16-25.

90. Michaels MG, Greenberg DP, Sabo DL, Wald ER. Treatment of children with congenital cytomegalovirus infection with ganciclovir. Pediatr Infect Dis J. 2003;22(6):504-508.

91. Lackner A, Acham A, Alborno T, et al. Effect on hearing of ganciclovir therapy for asymptomatic congenital cytomegalovirus infection: four to 10 year follow up. J Laryngol Otol. 2009;123(4):391-396.
92. Nassetta L, Kimberlin D, Whitley R. Treatment of congenital cytomegalovirus infection: implications for future therapeutic strategies. J Antimicrob Chemother. 2009;63(5):862-867.

93. Keller MA, Stiehm ER. Passive immunity in prevention and treatment of infectious diseases. Clin Microbiol Rev. 2000;13(4):602-614.

94. Griffith BP, Lavallee JT, Jennings TA, Hsiung GD. Transmission of maternal cytomegalovirus-specific immunity in the guinea pig. Clin Immunol Immunopathol. 1985;35(2):169-181.

95. Bratcher DF, Bourne N, Bravo FJ, et al. Effect of passive antibody on congenital cytomegalovirus infection in guinea pigs. J Infect Dis. 1995;172(4):944-950.

96. Nigro G, Adler SP, La Torre R, Best AM; for Congenital Cytomegalovirus Collaborating Group. Passive immunization during pregnancy for congenital cytomegalovirus infection. $N$ Engl J Med. 2005;353(13):1350-1362.

97. Nigro G, La Torre R, Pentimalli H, et al. Regression of fetal cerebral abnormalities by primary cytomegalovirus infection following hyperimmunoglobulin therapy. Prenat Diagn. 2008;28(6):512-517.

98. La Torre R, Nigro G, Mazzocco M, Best AM, Adler SP. Placental enlargement in women with primary cytomegalovirus infection is associated with fetal and neonatal disease. Clin Infect Dis. 2006;43(8):994-1000.

99. Schleiss MR. The role of the placenta in the pathogenesis of congenital cytomegalovirus infection: is the benefit of cytomegalovirus immune globulin for the newborn mediated through improved placental health and function? Clin Infect Dis. 2006;43(8):1001-1003.

100. Gabrielli L, Lega S, Foschini MP, et al. Histological and virological diagnosis of symptomatic congenital CMV infection in fetuses. The 2008 Congenital Cytomegalovirus Conference; 2008 Nov 5-7; Atlanta, Georgia. URL: http://www.rsvpbook.com/event_customization/CDC/Electronic\%20CMV\%20Program\%20Booklet.pdf. Accessed August 29, 2009.

101. Varani S, Frascaroli G, Landini MP, Söderberg-Nauclér C. Human cytomegalovirus targets different subsets of antigen-presenting cells with pathological consequences for host immunity: implications for immunosuppression, chronic inflammation and autoimmunity. Rev Med Virol. 2009;19(3):131-145.

102. Neff BJ, Weibel RE, Buynak EB, McLean AA, Hilleman MR. Clinical and laboratory studies of live cytomegalovirus vaccine Ad-169. Proc Soc Exp Biol Med. 1979;160:32-37.

103. Adler SP, Hempfling SH, Starr SE, Plotkin SA, Riddell S. Safety and immunogenicity of Towne stain cytomegalovirus vaccine. Pediat Infect Dis. 1998;17(3):200-206.

104. Plotkin SA, Starr SE, Friedman HM, et al. Effect of Towne live virus vaccine on cytomegalovirus disease after renal transplant. Ann Intern Med. 1991;114(7):525-531.

105. Adler SP, Starr SE, Plotkin SA, et al. Immunity induced by primary human cytomegalovirus infection protects against secondary infection among women of childbearing age. J Infect Dis. 1995;171(1):26-32.

106. Heineman TC, Schleiss M, Bernstein DI, et al. A phase 1 study of 4 live, recombinant human cytomegalovirus Towne/Toledo chimerc vaccines. $J$ Infect Dis. 2006;193(10):1350-1360.

107. Schleiss MR, Heineman TC. Progress toward an elusive goal: current status of cytomegalovirus vaccines. Expert Rev Vaccines. 2005;4(3):381-406.

108. Schleiss MR, Bourne N, Stroup G, Bravo FJ, Jensen NJ, Bernstein DI. Protection against congenital cytomegalovirus infection and disease in guinea pigs, conferred by a purified recombinant glycoprotein B vaccine. J Infect Dis. 2004;189(8):1374-1381.

109. Schleiss MR. Comparison of vaccine strategies against congenital CMV infection in the guinea pig model. J Clin Virol. 2008;41(3):224-230.

110. Pass RF, Zhang C, Evans A, et al. Vaccine prevention of maternal cytomegalovirus infection. N Engl J Med. 2009;360(12):1191-1199.

111. Schleiss MR, Bourne N, Bernstein DI. Preconception vaccination with a glycoprotein $\mathrm{B}(\mathrm{gB})$ DNA vaccine protects against cytomegalovirus (CMV) transmission in the guinea pig model of congenital CMV infection. J Infect Dis. 2003;188(12):1868-1874. 
112. Wloch MK, Smith LR, Boutsaboualoy S, et al. Safety and immunogenicity of a bivalent cytomegalovirus DNA vaccine in healthy adult subjects. J Infect Dis. 2008;197(12):1634-1642.

113. Jacobson MA, Adler SP, Sinclair E, et al. A CMV DNA vaccine primes memory immune responses to live-attenuated CMV (Towne strain). Vaccine. 2009;27(10):1540-1548.

114. Schleiss MR. VCL-CB01, an injectable bivalent plasmid DNA vaccine for potential protection against CMV disease and infection. Curr Opin Mol Ther. 2009;11(5):572-578.

115. Wang Z, La Rosa C, Li Z, et al. Vaccine properties of a novel marker gene-free recombinant modified vaccinia Ankara expressing immunodominant CMV antigens pp65 and IE1. Vaccine. 2007;25(6): $1132-1141$

116. Reap EA, Morris J, Dryga SA, et al. Development and preclinical evaluation of an alphavirus replicon particle vaccine for cytomegalovirus. Vaccine. 2007;25(42):7441-7449.
117. Schleiss MR, Lacayo JC, Belkaid Y, et al. Preconceptual administration of an alphavirus replicon UL83 (pp65 homolog) vaccine induces humoral and cellular immunity and improves pregnancy outcome in the guinea pig model of congenital cytomegalovirus infection. J Infect Dis. 2007;195(6):789-798.

118. Adler B, Scrivano L, Ruzcics Z, Rupp B, Sinzger C, Koszinowski U. Role of human cytomegalovirus UL131A in a cell type-specific virus entry and release. J Gen Virol. 2006;87(Pt 9):2451-2460.

119. Wang D, Shenk T. Human cytomegalovirus virion protein complex required for epithelial and endothelial cell tropism. PNAS 2005;102(50):18153-18158.

120. Cui X, Meza BP, Adler SP, McVoy MA. Cytomegalovirus vaccines fail to induce epithelial entry neutralizing antibodies comparable to natural infection. Vaccine. 2008;26(45):5760-5766.
International Journal of Women's Health

\section{Publish your work in this journal}

The International Journal of Women's Health is an international, peerreviewed open-access journal publishing original research, reports, reviews and commentaries on all aspects of women's healthcare including gynaecology, obstetrics, and breast cancer. Subject areas include: Chronic conditions (migraine headaches, arthritis, osteoporosis);

\section{Dovepress}

Endocrine and autoimmune syndromes; Sexual and reproductive health; Psychological and psychosocial conditions. The manuscript management system is completely online and includes a very quick and fair peer-review system. Visit http://www.dovepress.com/ testimonials.php to read real quotes from published authors.

Submit your manuscript here: http://www.dovepress.com/international-journal-of-womens-health-journal 